\title{
Towards a Social Trust-Aware Recommender for Teachers
}

Citation for published version (APA):

Fazeli, S., Drachsler, H., Brouns, F., \& Sloep, P. (2014). Towards a Social Trust-Aware Recommender for Teachers. In N. Manouselis, H. Drachsler, K. Verbert, \& O. C. Santos (Eds.), Recommender Systems for Technology Enhanced Learning: Research Trends and Applications (pp. 177-194). Springer.

https://doi.org/10.1007/978-1-4939-0530-0_9

\section{DOI:}

10.1007/978-1-4939-0530-0_9

Document status and date:

Published: 01/01/2014

Document Version:

Peer reviewed version

Please check the document version of this publication:

- A submitted manuscript is the version of the article upon submission and before peer-review. There can be important differences between the submitted version and the official published version of record. People interested in the research are advised to contact the author for the final version of the publication, or visit the DOI to the publisher's website.

- The final author version and the galley proof are versions of the publication after peer review.

- The final published version features the final layout of the paper including the volume, issue and page numbers.

Link to publication

\section{General rights}

Copyright and moral rights for the publications made accessible in the public portal are retained by the authors and/or other copyright owners and it is a condition of accessing publications that users recognise and abide by the legal requirements associated with these rights.

- Users may download and print one copy of any publication from the public portal for the purpose of private study or research.

- You may not further distribute the material or use it for any profit-making activity or commercial gain

- You may freely distribute the URL identifying the publication in the public portal.

If the publication is distributed under the terms of Article 25fa of the Dutch Copyright Act, indicated by the "Taverne" license above, please follow below link for the End User Agreement:

https://www.ou.nl/taverne-agreement

Take down policy

If you believe that this document breaches copyright please contact us at:

pure-support@ou.nl

providing details and we will investigate your claim.

Downloaded from https://research.ou.nl/ on date: 26 Apr. 2023 


\title{
Towards a Social Trust-aware Recommender for Teachers
}

\author{
Soude Fazeli, Hendrik Drachsler, Francis Brouns, Peter Sloep \\ Open Universiteit, Centre for Learning Sciences and Technologies, the Netherlands \\ soude.fazeli@ou.nl, hendrik.drachsler@ou.nl,francis.brouns@ou.nl, peter.sloep@ou.nl
}

\begin{abstract}
Online communities and networked learning provide teachers with social learning opportunities, allowing them to interact and collaborate with others in order to develop their personal and professional skills. However, with the large number of learning resources produced every day, teachers need to find out what are the most suitable ones for them. In this paper, we introduce recommender systems as a potential solution to this. The setting is the Open Discovery Space (ODS) project. Unfortunately, due to the sparsity of the educational datasets most educational recommender systems cannot make accurate recommendations. To overcome this problem, we propose to enhance a trustbased recommender algorithm with social data obtained from monitoring the activities of teachers within the ODS platform. In this article, we outline the requirements of the ODS recommender system based on experiences reported in related TEL recommender system studies. In addition, we provide empirical evidence from a survey study with stakeholders of the ODS project to support the requirements identified from a literature study. Finally, we present an agenda for further research intended to find out which recommender system should ultimately be deployed in the ODS platform.
\end{abstract}

Keywords. recommender system, collaborative filtering, social data, social networks, sparsity, trust, trust network, teacher, learning object

\section{Introduction}

The Internet provides teachers with a social space to interact and access resources in the form of either content or knowledgeable people outside their school (Brown and Adler 2008; Dawson 2008; Schuck 2003). However, with the increasing amount of user-generated content (e.g. in the form of learning resources, videos, discussion forums, blogs, etc.) produced every day, it becomes ever more difficult for teachers to find the most suitable content for their needs. Recommender systems have been introduced in the educational domain as a practical approach to solve information overload problems (Manouselis et al. 2012). Generally speaking, recommender systems provide a user with the most suitable content based on their past behaviour. They have become popular because of their successful applications in the e-commerce world such as by Amazon ${ }^{1}$ and $\mathrm{eBay}^{2}$. Fortunately, they can be adjusted and successfully

${ }^{1} \mathrm{http}: / /$ www.amazon.com 
used also in the educational domain as proven in the latest state of the art report by Manouselis, Drachsler, Verbert and Duval (2012). In this research, we investigate which recommender system algorithm suits the information overload problem of teachers best. The algorithm to be selected feeds on the activities of the teachers within an online social platform. The platform in this research is to be provided by the FP7 Open Discovery Space $^{3}$ (ODS) project. The ODS project aims to present a social network style platform that mainly aims to provide teachers with convenient accesses to approximately 1.550 .000 learning resources from several content repositories and educational portals all over the Europe.

In general, two methods have been used in recommender systems: content-based filtering and collaborative filtering. Content-based methods recommend an item to a user based on the similarity between the item's content description and the user's preferences model (Pazzani and Billsus 2007). Collaborative filtering algorithms try to find similar users based on the users' ratings and opinions. CF algorithms search for like-minded users that are introduced as neighbourhoods and they predict an item's rating for a target user based on collected ratings of the user's neighbours (Herlocker et al. 2004)(Schafer et al. 2007). In this research, we use collaborative filtering methods as we mainly focus on the interactions and collaborations between teachers within an online social platform. However, it is difficult to compute similarity of user profiles when users do not share a common set of ratings or when there are too few ratings available; this is known as the sparsity problem (Golbeck 2009; Schafer et al. 2007). Unfortunately, educational datasets suffer from this problem more often than commercial datasets (Verbert et al. 2011). Therefore, before we can even use recommender systems in learning, we need to find ways to overcome the sparsity problem.

Social trust has been introduced to many recommender systems as a response to the sparsity problem (Golbeck 2009; Kamvar et al. 2003; Lathia et al. 2008; Massa and Avesani 2007; Ziegler and Golbeck 2007). Trust has an important role in research areas as wide ranging as sociology, psychology, and computer sciences. Trust has many forms as it depends on many factors. In this research, we focus on trust in the context of social networks. In general, users prefer to receive recommendations from people they trust. Ziegler and Golbeck (2007) show a strong connection between trust and user similarity. In previous work, we utilized this when forming ad-hoc transient groups of similar users as a means of collectively solving content-related questions that learners experience (Van Rosmalen et al. 2008; Sloep 2009; Fetter et al. 2012). However, Golbeck (2009) shows that trust captures not only simple overall similarity between users but also other features of the relationships between users. In recommender systems research, trustworthy users have been introduced as the users who have shared positive experiences in the past (Golbeck 2009; Lathia et al. 2008; Lee and Brusilovsky 2009) and thus, trust is a value that reflects "a history of interactions rather than a history of similar ratings" (Lathia et al 2008).

\footnotetext{
${ }^{2} \mathrm{http}: / /$ www.ebay.com

${ }^{3}$ Open Discovery Space is a 7th framework European project, http://opendiscoveryspace.eu/
} 
Trust can help us to solve sparsity problem if it is assumed to be transitive; that is, if $A$ trusts $B$ and $B$ trusts $C$, then A trusts $C$. Assuming that trust is transitive allows us to find a relationship between two users who have no common set of items but do have friends in common. Suppose we have two users: Alice and Carol who have no rated set of items in common. Therefore, it is not possible to compute similarity between them. As a result, there will no direct relationship between Alice and Carol even though they are already indirectly connected through another user Bob. However, Carol might be a useful source of information for Alice and vice versa. In this case, the transitivity of the trust relationship helps us to infer a relationship between Alice and Carol through their common friend Bob: if Alice trusts Bob in his recommendations on papers and Bob also trusts Carol in the same way then, Alice can trust Carol in her recommendations on papers. It is important to note that the trust value between two users is computed based on their history of interactions that shows to what extent a user can trust the other. The initially assigned trust value will be gradually adjusted on the basis of users' interactions. In this way, the potential recommenders who provided valuable information to a user are trusted with higher degrees of trust and the users who could not be sources of information will be downgraded (Lathia et al. 2008). So, this is how we define "trust" in this research: trust is a transitive relation between users who share a history of interactions. Although trust defined this way is different from many other, social or psychological definitions, it is sufficiently similar to them to be useful in realistic contexts.

In teachers' communities, teachers can perhaps be supported to find trustworthy resources as proxies for reliable sources of information. Such trustworthy resources enable teachers to feel more comfortable to share and interact within a closed and trustful community. To achieve this, we follow a trust-based recommender system proposed by Fazeli et al. (2010) to create trust networks of users based on the rating information of user profile and item profile. Fazeli et al. proposed a concept called Tindex to measure trustworthiness of users in order to improve the process of finding the nearest neighbours. The T-index is inspired on the H-index, which is used to evaluate the impact of publications (Hirsch 2005). In the present context, the higher the Tindex value of a user, the more trustworthy that user becomes. Fazeli et al. showed how the T-index improves the structure of a generated trust network of users by creating connections to more trustworthy users (Fazeli et al. 2010). Trust networks of users are described as a graph in which nodes represent the users and directed edges show the trust relationships (Dokoohaki and Matskin 2008; Fazeli et al. 2010; Golbeck 2005). Fazeli et al. created the trust relationships between users based on the ratings users gave to the items in their system (Fazeli et al. 2010). Although user evaluations in the form of ratings is one of the important examples of users' activities within a social environment, other social activities of users should not be ignored up front. In general, the social activities of users describe each action of users within a social environment, for instance browsing a Web page, bookmarking, tagging, making a comment, giving rating, etc. We refer to the data that comes from the social activities of users, as social data. In this research, we aim to enhance the existing T-index approach of (Fazeli et al. 2010) by using social data of users. We intend to create trust 
relationship between users based on the collected social data from their activities within the ODS platform.

Therefore, the first research question is:

RQ1: Can the sparsity problem within educational datasets be solved by using inter-user trust relationships, which originally come from the social activities of users within an online environment, and, if so, how?

Moreover, we aim to study how the generated trust networks of users can be improved by social data of users. Therefore, we need to study the structure of trust networks for teachers and show how using trust relationships between users can have a positive effect on the generated trust networks of users. So, the second research question is:

RQ2: Can the use of the inter-user trust relationships that originally come from the social activities of users within an online environment, help teacher networks evolve?

The rest of this paper is organized as follows: Section 2 presents the state-of-the-art in recommender systems with the aim of exploring what characteristics should be taken into account when designing a recommender system. In Section 3, we describe the requirements analysis phase. We define a use case scenario as a practical example and then we validate the given use case with the collected data in a visionary workshop. Based on the requirements derived in Section 3, Section 4 presents an overview of on-going and future tasks in our research. Section 5 discusses our conclusions.

\section{State-of-the-art}

Several reviews exist which detail how to study and classify recommender systems in terms of recommendation techniques, tasks, delivery mode, etc. However, each of these reviews focuses only on some of the dimensions to classify recommender systems and none of them present an integrated framework for the classification of recommender systems (Manouselis et al. 2012). Manouselis and Costopoulou (2007) propose a framework for categorizing the dimensions of recommender systems, which were identified in the related studies. We will use this framework to investigate the characteristics that should be considered when designing a recommender system for teachers. As shown in Figure 1, the proposed framework consists of five main categories of characteristics: 1. Supported tasks, 2. User model, 3. Domain model, 4. Personalization, and 5. Operation. We will now introduce each of the characteristics briefly and conclude with how the resulting framework could be applied to a recommender system for teachers. 


\subsection{Supported Tasks}

As mentioned before, teachers need to stay informed about the availability of resources which may help them to deal with the issues they face in their job. So, we aim to support teachers to Find Novel Resources that are suitable for them based on their profile history. Most of the recommender systems in the educational domain have been designed to support this task (Drachsler et al. 2009; Lemire et al. 2005; Rafaeli et al.; Recker et al. 2003; Tang and McCalla 2003). For more examples, see the book by Manouselis, Drachsler, Verbert and Duval (2012).

\subsection{User model}

We represent user profiles for teachers by history-based models and user-item matrices which mainly focus on the past activities of the users, such as ratings information (Lemire et al. 2005; Manouselis et al. 2010; Recker et al. 2003). Furthermore, we aim to create user profiles based on ontologies as through their formal definition they provide us with more interoperability and openness between heterogeneous platforms. In addition, ontologies provide inference mechanisms, which may be used to enhance the recommender systems. We create the relationships between users by ontology to model the relationships between users on social networks (Dokoohaki and Matskin 2008; Fazeli et al. 2010; Golbeck 2005).

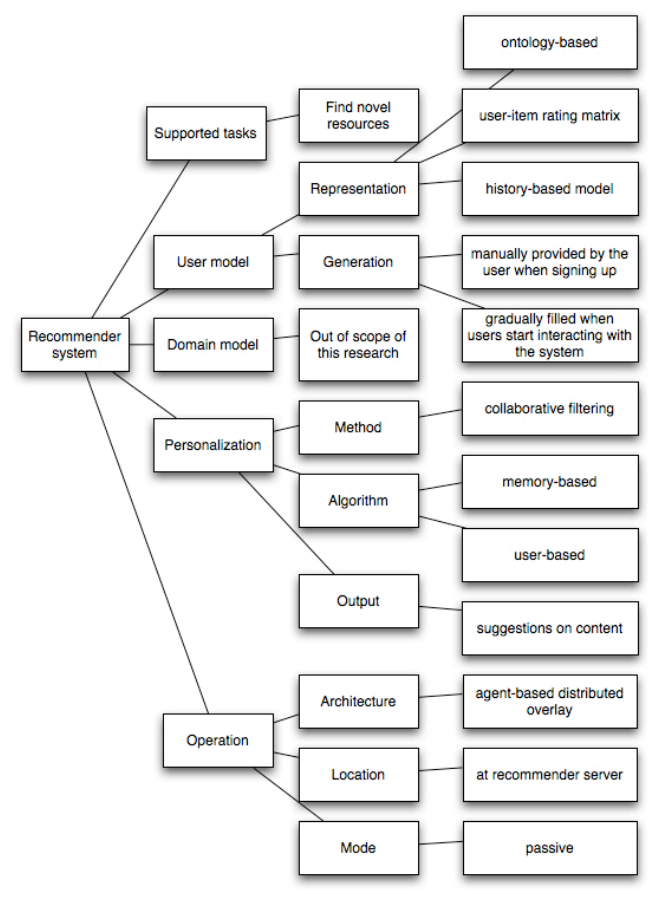

Fig. 1. A proposed social recommender system for teachers 
The user profiles for teachers are generated on the basis of information provided by the users when they themselves fill in a registration form with their personal information (name, surname, email, etc.) and professional information (teaching subject, interests, background knowledge, etc.). We refer to this part of the user profile as static data as it can be edited manually by the users anytime they want to. The other part of the user profiles contains dynamic or recommendation data. It will be dynamically updated by the system as soon as teachers start interacting with the system (see Fig. 1). Since our main objective is to support teachers with a recommender system in the educational domain, we have to take into account the teachers' characteristics. So, to create a user model for teachers, we need to consider both actions of teachers and context variables in the TEL field (Verbert et al. 2012). Verbert et al. describe the main characteristics that are to be considered for users in an educational context, such as knowledge level, interests, goals and tasks, and background knowledge, in addition to the data regarding users' actions in terms of type and result of actions and the context in which an action has been taken (Verbert et al. 2012).

As indicated, we intend to take advantage of social data of users to deal with the sparsity problem. To do so, we keep track of users' actions, so-called social activities, when they for instance rate, tag, bookmark, or share content in the ODS platform. In this way, the recommendations will be generated and improved based on the recorded actions of teachers while they interact with the ODS platform. As mentioned before, social data originally come from these recorded actions of users (teachers). To capture the social data, we intend to follow a standard specification to store and maintain users' actions. Several standard specifications to describe social data of users and guarantee their interoperability exist. They are:

- FOAF. The FOAF (Friend-of-a-Friend) vocabulary (Graves et al. 2007) describes user's information and their social connections through concepts and properties in form of an ontology using Semantic Web technologies (Golbeck 2005). The FOAF Vocabulary describes personal information and social relationships. The FOAF Vocabulary shows basic information of users (FOAF Basics) such as name, surname and also personal information about the people that a user "knows" and its interest area (Personal Info). In this research, we could extend the FOAF ontology to describe users by the concept of FOAF:agent that enables us to present our system in a distributed setting to provide more scalability. Several trust-based recommender systems have described the trust relationship between users by extending the FOAF ontology to model the social relationship between users (Fazeli et al. 2010; Golbeck 2005; Massa and Avesani 2007).

- CAM. Contextualized Attention Metadata (CAM) is a format to capture observations about users' activities with any kind of tool (Schmitz et al. 2009; Wolpers et al. 2007). A CAM schema aims to store whatever has attracted users' attention while the users are working with the tool. It also stores users' interaction with the tool such as rating, tagging, etc. A CAM schema records an event and its details when a user performs an action within a tool. The metadata stored in the CAM format describe all types of users' feedback and, therefore, can be used to make 
recommendations for the users. Platforms that have been developed based on CAM schema, allow users to remove the tags they already assigned to a learning object, or to modify the ratings value they already gave to a learning object. Although this kind of information can be useful when generating recommendations, we prefer to provide users with the updated information of a learning object and not with the history of removed tags, modified ratings, etc. (Niemann et al. 2012).

- Organic.Edunet. In the context of Organic.Edunet ${ }^{4}$, Manouselis and Vuorikari (2009) developed a model to represent and store users' feedback, including rating, tagging, reviewing, etc. in a structured, interoperable and reusable format. This model is also based on the CAM format and aims to transfer the social data of users between heterogeneous systems. The social data of users are stored and retrieved by help of a so-called Social Navigation Module that is also in charge of making recommendations based on user profiles. At the moment, the Organic.Edunet schema does not support social data of users other than the ones already implemented by the Social Navigation Module in forms of tags, ratings and reviews.

We have also reviewed other standard specifications to describe social data such as Learning registry paradata ${ }^{5}$ and NSDL paradata ${ }^{6}$ but they have been designed to store the usage data of a learning object in an aggregated manner. In other words, they do not specifically keep track of the individual actions of each user. In our research, we need to store and retrieve every single action of the users in order to make recommendations for them. This is why we selected the standard specifications mentioned above, that is FOAF, CAM, and Organic.Edunet schemas.

\subsection{Domain model}

Objects that are to be presented to teachers need to be represented somehow and need to be generated before they can be presented. This task is out of scope for the present research project. It will, parenthetically, be taken up by the ODS project, which aims to represent an integrated object repository containing several collections of learning objects hosted by the ARIADNE ${ }^{7}$ infrastructure. (The ODS intends to provide the largest European learning object repository in the field of education in 2015 including approximately 1.550 .000 learning resources from 75 content repositories and 15 educational portals.)

\subsection{Personalization}

Method. As we pointed out in Section 1, we use collaborative filtering methods because they purely depend on users' opinions and interactions and do not need the

\footnotetext{
http://portal.organic-edunet.eu/

$\mathrm{http}: / / \mathrm{www}$.learningregistry.org/documents/starter-resources

$\mathrm{http}: / / \mathrm{www}$.learningregistry.org/community/nsdl

$\mathrm{http} / / /$ www.ariadne-eu.org/repositories
} 
actual content descriptions required by content-based methods. We intend to enhance the trust-based collaborative filtering approach of (Fazeli et al. 2010) by using social data of users within the ODS platform.

Algorithm. CF methods are often categorized according to type or technique. Type refers to memory-based and model-based algorithms (Manouselis and Costopoulou 2007; Schafer et al. 2007). Model-based algorithms use probabilistic approaches to develop a model of a user from the user's history and profile. Examples of modelbased algorithms are Bayesian networks, neural networks, and algebraic approaches such as eigenvectors (Kamvar et al. 2003). Although these algorithms are faster than memory-based algorithms, they require a full set of users' preferences to develop user models; such a set is often not available. Moreover, model-based algorithms are often very costly for learning and updating phases. Instead, memory-based algorithms are quite straightforward to use. They find correlations between users based on statistical techniques for measuring similarity, such as Pearson correlations or Cosine similarities (Breese et al. 1998). As they are more straightforward, we use memory-based algorithms in this research. In case the pure memory-based algorithms do not scale well in real-life applications, we combine them with some pre-computation to reduce the run-time complexity (Schafer et al. 2007).

The technique of $\mathrm{CF}$ algorithms often refers to user-based and item-based algorithms (Manouselis and Costopoulou 2007; Schafer et al. 2007). User-based algorithms try to find patterns of similarity between users in order to make recommendations, and item-based algorithms follow the same process but are based on similarity between items (Schafer et al. 2007). In this research, we are interested in user-based algorithms because we focus on users interactions and activities within an online social environment such as the ODS platform.

Output. The majority of the recommender systems generate recommendations in the form of suggestions on content or people, or sometimes ratings (Beham et al. 2010; Drachsler et al 2009; Recker et al. 2003). Another common output of recommender systems is predictions of a rating value that a user would give to an item (Schafer et al. 2007). In this research, we currently focus on recommending content to the teachers in the context of the ODS platform. As a further step, we aim to make suggestions on people as well.

\subsection{Operation}

In the TEL domain, most of the recommender systems follow a centralized architecture, in which a central recommender server provides access to a single learning object repository; only a few are based on a distributed architecture (Manouselis et al. 2012). In this research, we intend to follow the agent-setting distributed approach by (Fazeli et al. 2010) to provide more scalability if the number of users were to increase. Fazeli et al. describe each user by extending the FOAF agent concept (Dokoohaki and 
Matskin 2008; Fazeli et al. 2010; Golbeck 2005). As a result, each user can be viewed as a peer in a distributed setting such as peer-to-peer networks.

The recommendations are to be made at the recommender server (location) and are to be sent to the users as a part of their natural interactions within the ODS platform, e.g. when a user browses a page or rates a learning object. In this way, users do not need to ask for recommendations explicitly; this is referred to as passive mode (Schafer et al. 2007). Thus, users receive recommendations on learning objects they make an action such as browsing, rating, tagging, etc. within the ODS platform.

\section{Requirement analysis}

In this research, we follow the methodology described by Manouselis, Drachsler, Verbert and Duval for recommender systems in TEL (Manouselis et al. 2012). We extended this methodology by first conducting a survey study with teachers in the context of the ODS summer school for European teachers in Greece, July 2012. We there asked them to fill in a questionnaire regarding the importance or usefulness of the activities within an online social platform and also regarding the use of recommender systems. The questionnaire consists of questions about the use of social data and recommender systems by teachers e.g. "Do you find sharing of content on Facebook, Twitter, etc. or by email important, useful or useless". Moreover, the designed questionnaire includes questions about how teachers think of recommender systems.

In the following subsections, we will first describe a use case scenario for a teacher called Irma, to identify the main requirements; then, we will discuss the results we achieved based on the Irma use case scenario. The results present a list of the most important needs and requirements of teachers within an online social environment such as the ODS platform.

\subsection{Irma: a teacher from the Netherlands}

We created a use case scenario for a staring teacher in math and physics at a secondary school in the Netherlands (Drachsler et al. To appear). We call her Irma. Figure 2 shows a UML use case diagram to describe her activities within the ODS platform.

Irma has just started to work as a teacher and as a new teacher she faces several challenges every day at her school. An official mentor was already assigned to her to have weekly meetings but she still does not feel confident. She would like to get in touch with other teachers, mentors, experts, and novices, to share her concerns with them. Sometimes it is not even clear to her what the problem is and how she can formulate it when she has official meetings with her mentor. So, she needs to hear how things went with the other teachers, what were their main challenges when they started their job, and how they tackled those issues. She is quite curious to know if there is somebody out there who is in a situation similar to hers and, if so, whether they could exchange information. Moreover, she is very interested to know how she could innovate her teaching in her classroom to attract and motivate the pupils and to make the atmosphere of the classroom more entertaining. Irma has just seen an advertisement 
about a social platform for teachers called the ODS platform. She decides to check it out and she first uses the search mechanism by entering a few keywords to explore the available learning resources related to her teaching subject. She browses the results and selects a couple of them that look interesting to her. If she so wishes, the platform allows her to share the interesting ones with others on the social networking sites such as Facebook or Twitter, or simply by sending emails to them.

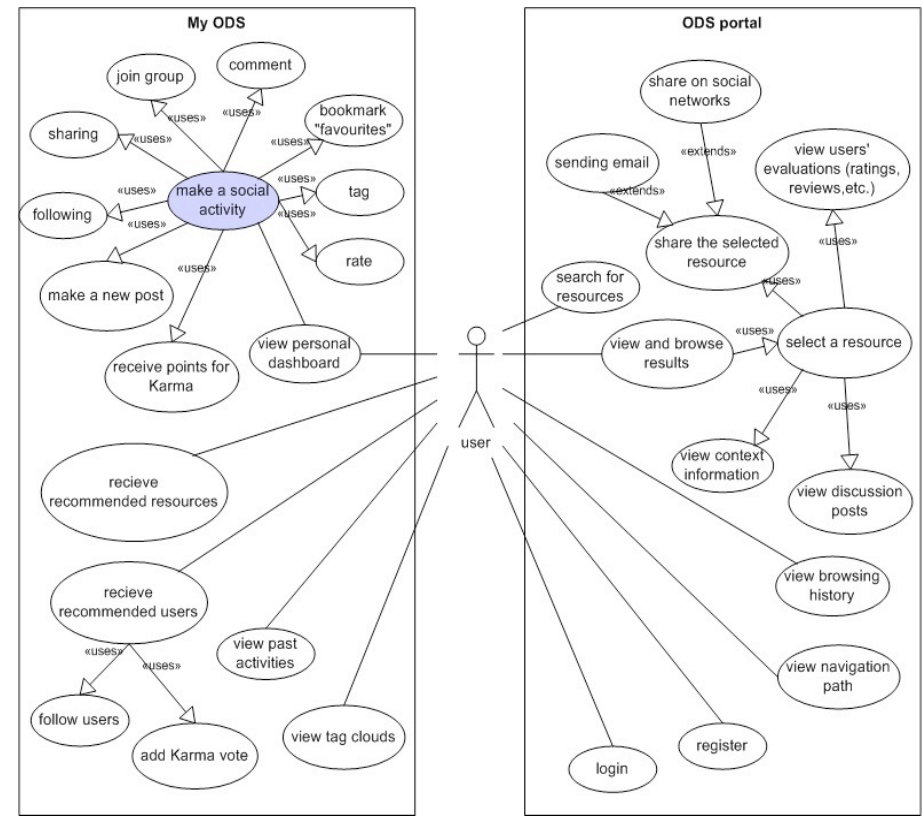

Fig. 2. Irma use case diagram

Whenever Irma happens to find a learning resource, she can see the evaluations of other users (ratings, reviews, etc.) and the discussion posts connected to the selected learning resource. Irma finds several groups related to the discussion posts that attracted her and she feels quite motivated to participate in discussions because that is exactly what she has been looking for. To do so, Irma has to become a member first, to be allowed to go to the "My ODS" (shown in Fig. 2). So, she fills in a registration form and becomes a member. Now, she can join groups that interest here and participate in discussions. She can rate, tag, bookmark the learning resources and make comments as part of her activities within the ODS as a social platform (note that this we referred to as social activities of a user). The more she contributes to the social activities, the more points she receives for her 'Karma', that shows her potential for being a trustworthy user. Furthermore, Irma sees a personal dashboard on the "My ODS" page where she receives recommendations on learning resources that might be of interest to her. That is particularly useful when she is not quite sure about the exact keywords she has to enter when searching for learning resources. Irma becomes even happier when she sees a list of recommended people for her based on her past activi- 
ties and profile. She browses the list and finds experts, mentors, and other novices among them with whom she would like to get in touch. So, she chooses to "follow" them in order to see what kind of social activities they have been engaging in within the ODS platform e.g. if they rated, bookmarked, tagged resources and if they posted a new discussion in a particular group. Based on their activities, Irma can add to their Karma vote. After checking out the ODS platform, Irma now feels much more confident to see that there is much suitable content and there are many interesting people in the ODS for her. (For a more detailed use case scenario, please refer to the ODS deliverable 8.1 (Drachsler et al. To appear).

\subsection{Validation of Irma use case}

To validate the Irma use case, we took advantage of a summer school for European teachers that was held in Greece, July 2012 in the context of the ODS. We first presented the Irma use case to the participants of a visionary workshop, and followed that up with discussions on the use case. Then, we asked the participating teachers to fill in a questionnaire consisting of statements about social activities and recommender systems. The intention was to find out if the participating teachers would find them useful or important for their personal and professional development. In total, 33 teachers participated in the survey study; they came from 14 countries (Portugal, Germany, France, Finland, Greece, Austria, Poland, Lithuania, Spain, Hungary, Romania, Cyprus, Ireland, Serbia and the US). From each country 2 teachers participated except for Spain and Hungary with 5 and 4 participants, respectively. The majority of participants were secondary school teachers $(73 \%)$ while there were also representatives from primary schools $(6 \%)$, teacher trainers $(6 \%)$ and trainees $(27 \%)$, university lecturers $(6 \%)$, museum educators $(6 \%)$, curriculum developers $(3 \%)$ and educational policy makers $(6 \%)$. Some of the participating teachers indicated that they had more than one role. 18 female and 15 male teachers participated. Participants came from different age ranges: $20-30$ years old teachers $(25.2 \%), 31-40$ years old $(33.4 \%), 41$ 50 years old $(22.2 \%)$ and over 50 years old $(19.2 \%)$.

Fig. 3 shows the degree to which the participating teachers found it useful or important that the social activities displayed on the horizontal axis be provided within a social platform like the ODS. All of them agreed that the possibility to share content via social networks such as Facebook or Twitter is very important. In the second place, around $97 \%$ of the teachers found recommending content to somebody like a friend or colleague quite useful. Moreover, almost $80 \%$ of the participants thought that it is important to be able to tag the content by keywords, to rate the content, to follow other users, and to follow/participate existing groups in an online social platform. For around $65 \%$ of participating teachers bookmarking content seemed to be a useful activity. On average, $53 \%$ of the teachers thought that it is useful to comment, to create groups, and to report inappropriate content or a broken link.

In total, more than $50 \%$ of the participants found most of social activities important or useful. It shows how much the teachers are interested in the social features that the ODS platform is to provide to them. 


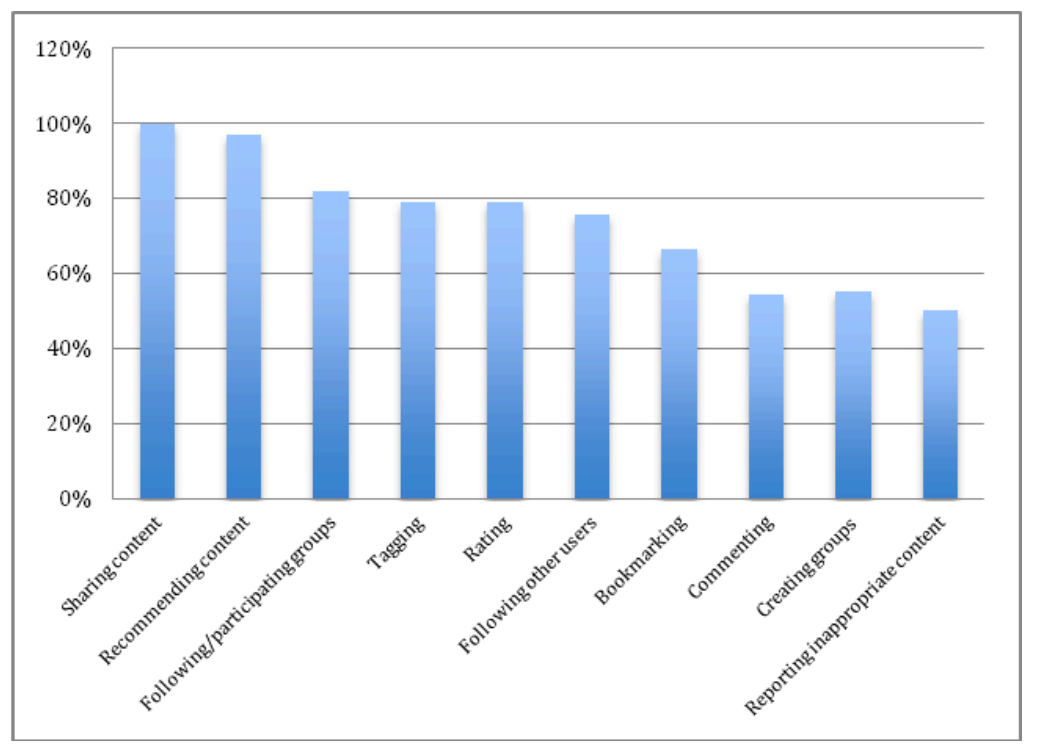

Fig. 3. How much the teachers find the online social activities important/useful

In addition to the results shown in Fig. 3, we asked the teachers some more detailed questions about receiving recommendations, as well as about privacy issues in a an online social platform. Figure 4 presents the results of what the participating teachers found important or useful and the degree to which they thought so. It shows that privacy issues are quite important for most of the teachers. They want to know with whom they share content and information, and also who can see their profile. Therefore, they need to be able to control their privacy settings in an online social platform. Moreover, $91 \%$ of the participating teachers found it important to recognize how much they can trust the other users e.g. with respect to the content other users shared with them. The planned extension of the trust-based recommender (Section 2.4) will ensure that some user is introduced to the other users in trust networks by the assigned T-index, which bases itself on that user's contributions and history. This will then also enable us to address these requirements.

Fig. 4 furthermore shows that $81 \%$ of the participating teachers preferred to receive recommendations from their friends, friends of friends, or from those with a career similar to theirs. In the terminology of social networks, the teachers preferred to receive recommendations from those who are connected to them either directly or indirectly through their intermediate friends. As described in Section 2.4, we intend to generate recommendations by traversing the trust networks of users created by following the T-index approach (Fazeli et al. 2010). So, the collected recommendations for a target user will be collected from those who are connected to them either directly or indirectly through their intermediate friends. As a result, the generated recommendations within our system will be capable of meeting the above requirements that have been indicated as important by $81 \%$ of the participating teachers. 
According to Fig. 4, 70\% of the participating teachers found it useful to receive recommendations that are automatically generated based on their profile. In other words, the teachers prefer to receive recommendations without the need of asking for recommendations explicitly. As indicated in Section 2.5, we aim to generate the recommendations automatically on users' social activities such as rating, tagging, browsing, etc. within the ODS platform. This enables us to fulfil the need of receiving automatically generated recommendations pointed out as important by $70 \%$ of the teachers.

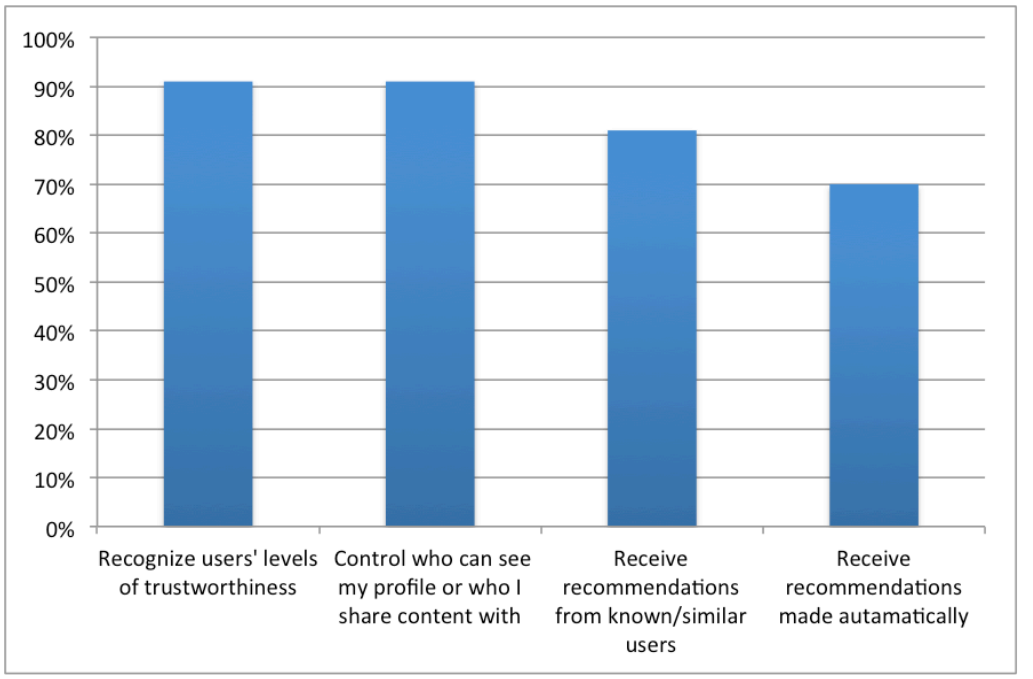

Fig. 4. How much teachers find the detailed requirements important/useful

\section{$4 \quad$ On going and future research}

Section 3 described our requirements analysis as the first step of our research method. This section now presents next steps that should be taken.

\subsection{Data study}

The main goal is to find a recommender system algorithm that best covers the requirements for teachers derived in Section 3. To uncover what is best, we will conduct an offline empirical study of different recommender system algorithms on a selected collection of representative datasets. The study will be in terms of the metrics that are most often used to evaluate the performance of recommender systems, such as prediction accuracy of the generated recommendations. In addition, we aim to study the structure of the trust networks of users when using the trust-based recommender system (Fazeli et al. 2010). The network's structure will be evaluated in terms of indegree distribution (for some node on a network, the indegree describes the number of incoming edges to that node). In this research, we can interpret the indegree of a user within a network, as the number of users that already trusted the user. In gen- 
eral, we are interested in a balanced indegree distribution that can have a positive effect on users' mutual interactions and their contributions. Initial results will indicate which of the recommender algorithms suits teachers best and if the trust-based recommender system can indeed help to deal with the problem of sparse data exhibited by the datasets used.

Based on the requirement analysis described in Section 3, we selected the following educational datasets as our candidate datasets to be studied (Verbert et al 2011): Travel well, MACE, OpenScout, MERLOT. The planned study will evaluate a set of different classical CF algorithms next to the trust-based algorithm (Fazeli et al 2010) on a variety of educational datasets. An issue with the educational datasets is that most of them are not publicly available. Moreover, unfortunately, there is no golden standard dataset in the educational domain such as is the MovieLens dataset $^{8}$ in the ecommerce world. For instance, for the Travel well dataset, different versions are available. In fact, no unique version has been singled out for running the experiments, nor for making a comparison in the recommender system community. To address these issues, the dataTEL project proposed to establish a set of representative datasets as a reference for running data-driven studies in the educational domain (Drachsler et al. 2011).

\subsection{User evaluation study}

Having identified the most promising recommendation algorithms based on the data study, we will develop the initial recommender system for the ODS project. We will run a user evaluation study at one of the upcoming ODS summer schools to study usability of the prototype by evaluating users' satisfaction. Through a questionnaire the end-users will be asked to provide feedback on the prototype. Questions asked will be how interesting the end-users find the recommended content and how recommended content can help users to gain new knowledge or improve their current knowledge (Tang and McCalla 2009).

Based on the outcomes, the prototype will be customized and improved so as to be able to deploy an improved release for an extended pilot study with a large number of European teachers as the ODS real users. Initial feedback by end-users on usability of the prototype is the outcome we expect.

\subsection{Pilot study}

Ultimately, we aim to deploy a stable release that will be tested under realistic and standard operational conditions with the end-users. To do so, we compare the performance of a proposed recommender system based on our presented framework with classical collaborative filtering algorithms. Furthermore, we aim to study the structure of the teachers' networks to investigate how networks of teachers will evolve by the use of social data. To evaluate the effectiveness of the proposed recommender system,

\footnotetext{
${ }^{8} \mathrm{http}: / /$ www.grouplens.org/node/73
} 
we will compare the results in terms of the total number of learning objects which have been visited, bookmarked, rated, etc. for two groups of users:

- Those who are aided by recommender systems to access learning objects

- Those who access learning objects directly from the repository, without the help of a recommender system.

We will measure prediction accuracy, coverage and F1 measure of the generated recommendations, effectiveness in terms of total number of learning objects visited, bookmarked, or rated, as well as indegree distribution. The last will be used to study how the structure of the networks changes. Once the results are in, we expect to find out whether our proposed recommender system outperforms the classical CF algorithms. An important concomitant outcome will be the visualization of teachers' networks, to show how the network's structure evolves when relying on inter-user trust relationships that come from the social data of users.

\section{Conclusion}

In this paper, we introduced recommender systems as a potential way to support teachers in finding content that matches their needs and interests. We also argued that we likely need to overcome the sparsity problem, which hinders recommender systems in the educational domain. Therefore, we presented two research questions and research method that mainly focus on ways to tackle the sparsity problem. Social trust is a key concept here. The results of a requirement analysis presented in this paper were consistent with the main requirements described by a use case scenario. The results indicated that the majority of the teachers are interested in online social activities such as rating, tagging, bookmarking, sharing the content, commenting, following other users, etc. Moreover, the results show that teachers prefer to receive recommendations from trustworthy users in particular. This requirement underscores the use of social trust when designing a recommender system for teachers.

Besides recommending the most suitable content to teachers, we plan to support teachers to find the peers with whom they can share their concerns and, in general, exchange knowledge.

Acknowledgment. This paper is part of a doctoral study funded by NELLL (the Netherlands Laboratory for Lifelong Learning at the OUNL) and the Open Discovery Space project. Open Discovery Space is funded by the European Union under the Information and Communication Technologies (ICT) theme of the 7th Framework Programme for R\&D. This document does not represent the opinion of the European Union, and the European Union is not responsible for any use that might be made of its content. 


\section{References}

Beham G, Kump B, Ley T, Lindstaedt S (2010) Recommending knowledgeable people in a work-integrated learning system. Procedia Computer Science 1:2783-2792.

Breese JS, Heckerman D, Kadie C (1998) Empirical analysis of predictive algorithms for collaborative filtering. In Proceedings of the 14th Conference on Uncertainty in Artificial Intelligence (UAI 1998). pp 43-52

Brown JS, Adler RP (2008) Minds on Fire: Open Education, the Long Tail, and Learning 2.0. EDUCAUSE Review, 43(1), 16-32

Dawson S (2008) A study of the relationship between student social networks and sense of community. Educational Technology \& Society 11:224-238.

Dokoohaki N, Matskin M (2008) Effective design of trust ontologies for improvement in the structure of socio- semantic trust networks," International Journal On Advances in Intelligent Systems. International Journal On Advances in Intelligent Systems 1:23-42.

Drachsler H, Greller W, Fazeli S, et al. Review of Social Data Requirements, Deliverable 8.1, Open Discovery Space (ODS). To appear.

Drachsler H, Verbert K, Sicilia M-A, et al. (2011) dataTEL - Datasets for Technology Enhanced Learning - White Paper.

Drachsler, H., Pecceu, D., Arts, T., Hutten, E., Rutledge, L., Van Rosmalen, P., Hummel, H.G.K., Koper R (2009) ReMashed - Recommendations for Mash-Up Personal Learning Environments. In: Cress, U., Dimitrova, V., Specht M (ed) Learning in the Synergy of Multiple Disciplines, Proceedings of the 4th European Conference on Technology Enhanced Learning (EC-TEL 2009). Springer-Verlag, Berlin, Heidelberg, Berlin, pp 788793

Fazeli S, Zarghami A, Dokoohaki N, Matskin M (2010) Elevating Prediction Accuracy in Trust-aware Collaborative Filtering Recommenders through T-index Metric and TopTrustee lists. JOURNAL OF EMERGING TECHNOLOGIES IN WEB INTELLIGENCE 2:300-309. doi:10.4304/jetwi.2.4.300-309

Fetter, S, Berlanga, A J, Sloep, P B, Van der Vegt, W, Rajagopal, K, Brouns, F (2012) Using Peer-Support to Connect Learning Network Participants to Each Other: An Interdisciplinary Approach. International Journal of Learning Technology 7(4) 378-399. doi:10.1504/IJLT.2012.052212.

Golbeck J (2009) Trust and Nuanced Profile Similarity in Online Social Networks. Human Factors. doi: 10.1145/1594173.1594174

Golbeck J (2005) Computing and applying trust in web-based social networks. University of Maryland at College Park, College Park, MD, USA

Graves M, Constabaris A, Brickley D (2007) FOAF: Connecting People on the Semantic Web. Special issue on Knitting the Semantic Web 43:191-202. doi: 10.1300/J104v43n03_10

Herlocker JL, Konstan JA, Terveen LG, Riedl JT (2004) Evaluating collaborative filtering recommender systems. ACM Transactions on Information Systems 22:5-53.

Hirsch JE (2005) An index to quantify an individual's scientific research output. Proc Natl Acad Sci USA. doi: arXiv:physics 0508025

Kamvar SD, Schlosser MT, Garcia-Molina H (2003) The Eigentrust algorithm for reputation management in P2P networks. Proceedings of the twelfth international conference on World Wide Web - WWW '03. ACM Press, New York, New York, USA, p 640 
Lathia N, Hailes S, Capra L (2008) Trust-Based Collaborative Filtering. Trust Management II, IFIP Advances in Information and Communication Technology. doi: DOI: 10.1007/978-0387-09428-1_8

Lee DH, Brusilovsky P (2009) Does Trust Influence Information Similarity? In Proceedings of the Workshop on Recommender Systems and the Social Web (RSWEB'09). pp 3-6

Lemire D, Boley H, McGrath S, Ball M (2005) Collaborative filtering and inference rules for context-aware learning object recommendation. Interactive Technology and Smart Education 2:179-188.

Manouselis N, Costopoulou C (2007) Analysis and Classification of Multi-Criteria Recommender Systems. WorldWideWeb: Internet and Web Information Systems 10(4):415-441.

Manouselis N, Drachsler H, Verbert K, Duval E (2012) Recommender Systems for Learning. 1-61. doi: DOI: 10.1007/978-1-4614-4361-2

Manouselis N, Vuorikari R (2009) What If Annotations Were Reusable: A Preliminary Discussion. In: Spaniol M (ed) Proceedings of the 8th International Conference on Advances in Web-Based Learning - ICWL 2009. Berlin Heidelberg: Springer-Verlag, pp $255-264$

Manouselis N, Vuorikari R, van Assche F (2010) Collaborative Recommendation of e-Learning Resources: An Experimental Investigation. Journal of Computer Assisted Learning 26:227242.

Massa P, Avesani P (2007) Trust-aware recommender systems. Proceedings of the 2007 ACM conference on Recommender systems - RecSys '07. ACM Press, New York, New York, USA.

Niemann K, Scheffel M, Wolpers M (2012) A Comparison of Usage Data Formats for Recommendations in TEL. Proceedings of the 2nd Workshop on Recommender Systems in Technology Enhanced Learning (EC-TEL 2012)

Pazzani MJ, Billsus D (2007) Content-Based Recommendation Systems. THE ADAPTIVE WEB Lecture Notes in Computer Science 4321/2007:325-341. doi: 10.1007/978-3-54072079-9_10

Rafaeli S, Dan-Gur Y, Barak M (2005) Social Recommender Systems: Recommendations in Support of E-Learning. 3: 2005. doi: DOI: 10.4018/jdet.2005040103

Recker MM, Walker A, Lawless K (2003) What do you recommend? Implementation and analyses of collaborative information filtering of web resources for education. Instructional Science 31:299-316. doi: 10.1023/A:1024686010318

Schafer JB, Frankowski D, Herlocker J, Sen S (2007) Collaborative Filtering Recommender Systems. The Adaptive Web Lecture Notes in Computer Science 4321/2007:291-324. doi: DOI: 10.1007/978-3-540-72079-9_9

Schmitz H, Scheffel M, Friedrich M, et al. (2009) CAMera for PLE. 5794/2009:507-520.

Schuck S (2003) Getting help from the outside : developing a support network for beginning teachers. 4:49-67.

Sloep PB (2009) Fostering Sociability in Learning Networks through Ad-Hoc Transient Communities. In: Purvis M, Savarimuthu BTR (eds) Computer-Mediated Social Networking, ICCMSN 2008, LNAI 5322. Springer, Berlin, Heidelberg, pp 62-75. 
Tang T, McCalla G (2003) Smart Recommendation for an Evolving E-Learning System. Workshop on Technologies for Electronic Documents for Supporting Learning, International Conference on Artificial Intelligence in Education (AIED 2003).

Tang T Y, McCalla G (2009) The Pedagogical Value of Papers: a Collaborative-Filtering based Paper Recommender. Journal of Digital Information; Social Information Retrieval for Technology Enhanced Learning

Van Rosmalen P, Sloep PB, Brouns F, et al. (2008) A model for online learner support based on selecting appropriate peer tutors. Journal of Computer Assisted Learning 24:483-493. doi: $10.1111 /$ j.1365-2729.2008.00283.x

Verbert K, Drachsler H, Manouselis N, et al. (2011) Dataset-driven research for improving recommender systems for learning. Proceedings of the 1st International Conference on Learning Analytics and Knowledge. ACM, New York, NY, USA., pp 44-53

Verbert K, Manouselis N, Drachsler H, Duval E (2012) Dataset-driven Research to Support Learning and Knowledge Analytics. Educational Technology and Society, Special Issue on Learning and Knowledge Analytics 15:133-148.

Vuorikari R, Massart D (2009) dataTEL challenge : Europen Schoolnet's Travel well dataset Application / environment.

Wolpers M, Najjar J, Verbert K, Duval E (2007) Tracking Actual Usage: the Attention Metadata Approach. Educational Technology \& Society 10:106-121.

Ziegler C-N, Golbeck J (2007) Investigating interactions of trust and interest similarity. Decision Support Systems 43:460-475. doi: 10.1016/j.dss.2006.11.003 